\title{
Compositional homogeneity in a medical-grade stainless steel sintered with a Mn-Si additive
}

\author{
E. Salahinejad ${ }^{\text {a,*, }}$, M.J. Hadianfard ${ }^{\text {a }}$, M. Ghaffari ${ }^{\text {b.c }}$, Sh. Bagheri Mashhadi ${ }^{\text {a }}$, A.K. Okyay ${ }^{\text {b }}$ \\ a Department of Materials Science and Engineering, School of Engineering, Shiraz University, Zand Blvd., 7134851154, Shiraz, Iran \\ ${ }^{\mathrm{b}}$ Department of Electrical and Electronics Engineering, UNAM-National Institute of Materials Science and Nanotechnology, Bilkent University, Ankara 06800, Turkey \\ ' School of Electrical and Electronic Engineering, Micro Electronic Division, Nanyang Technological University, Nanyang Avenue, Singapore 639798, Singapore
}

\section{A R T I C L E I N F O}

\section{Article history:}

Received 12 March 2012

Received in revised form 30 April 2012

Accepted 5 June 2012

Available online 9 June 2012

\section{Keywords:}

Medical-grade stainless steel

Sintering

Local chemical composition

Electron microscopy

Energy dispersive X-ray spectroscopy

\begin{abstract}
A B S T R A C T
In this paper, chemical composition uniformity in amorphous/nanocrystallization medical-grade stainless steel (ASTM ID: F2581) sintered with a Mn-Si additive was studied via scanning electron microscopy, energy dispersive X-ray spectroscopy, and transmission electron microscopy. The results show that as a result of sintering at $1000^{\circ} \mathrm{C}$, no dissociation of Mn-Si additive particles embedded in the stainless steel matrix occurs. In contrast, sintering at $1050^{\circ} \mathrm{C}$ develops a relatively homogeneous microstructure from the chemical composition viewpoint. The aforementioned phenomena are explained by liquation of the Mn-Si eutectic additive, thereby wetting of the main powder particles, penetrating into the particle contacts and pore zones via capillary forces, and providing a path of high diffusivity.
\end{abstract}

(C) 2012 Elsevier B.V. All rights reserved.

\section{Introduction}

Stainless steels, especially austenitic stainless steel AISI 316L containing nickel, are conventionally used in medical applications because of their low price compared to other metallic biomaterials. However, the harmful effects of nickel ions released from these implants have provided a high level of motivation for the development of nickel-free stainless steels [1]. In the ASTM standards, two austenitic nickel-free medical-grade stainless steels have been imported: ASTM ID: F2229 and ASTM ID: F2581. In the recent years, in vitro and in vivo studies have been conducted on the latter from the viewpoints of biocompatibility, osseointegration, and corrosion behaviors [2-7]. Powder metallurgy, the technology of developing solid components from powder via compaction and sintering, can be considered to process this type of materials with different properties and performances.

It is well established that to meet the best mechanical and corrosion behaviors of powder metallurgy parts, high densities are imperative. To do so, a number of approaches like warm compaction, increasing sintering temperature and time, and using proper additives to activate liquid-phase sintering are consideration. In the liquid-phase sintering process using sintering aids, the formation of a liquid phase promotes densification via providing a particle rearrangement, faster diffusion rate, and pore elimination [8,9]. Since solid-state sintering of stainless steels to obtain high densities demands high temperatures generally

\footnotetext{
* Corresponding author. Tel.: +98 917 3879390; fax: +98 7112307293.

E-mail address: erfan.salahinejad@gmail.com (E. Salahinejad).
}

more than $1300{ }^{\circ} \mathrm{C}[10,11]$, the liquid-phase sintering process lowering sintering temperature and time is a promising field from the scientific and technological viewpoints for this type of materials.

For liquid-phase sintering of stainless steels, additives like $\mathrm{Cu}, \mathrm{Sn}, \mathrm{Ni}$, $\mathrm{Pt}, \mathrm{Ag}, \mathrm{Si}, \mathrm{Au}, \mathrm{B}, \mathrm{P}$, their compounds and alloys have been experimented $[8,9]$. But note that for biomedical applications, the use of biocompatible sintering aids is reasonable. Recently, a novel biocompatible additive (Mn-11.5 wt.\% Si) was experimented to active liquid-phase sintering in a nickel-free medical-grade stainless steel (ASTM ID: F2581 [12,13]. However, microstructural uniformity from the chemical composition viewpoint, as an important structural feature affecting the material performance, at different sintering temperatures when using this additive was not focused. In this work, compositional homogeneity in mechanically-alloyed stainless steel (ASTM ID: F2581) sintered with $\mathrm{Mn}-\mathrm{Si}$ additive is evaluated via electron microscopy and energy dispersive X-ray spectroscopy.

\section{Experimental procedure}

Stainless steel (Fe-17Cr-10Mn-3Mo-0.4Si-0.5N-0.2C in wt.\%, ASTM ID: F2581) and Mn-11.5 wt.\% Si eutectic alloy powders were separately synthesized by ball milling of $\mathrm{Fe}, \mathrm{Cr}, \mathrm{Mn}, \mathrm{Mo}, \mathrm{Si}$, and $\mathrm{C}$ (Merck) and iron nitride (Alfa Aesar) powders. Milling was conducted in a planetary ball mill with a ball-to-powder weight ratio of 20:1 at a rotation speed of $500 \mathrm{rpm}$ for $48 \mathrm{~h}$ under an argon atmosphere. Four bearing steel balls of $20-\mathrm{mm}$ and twelve bearing steel balls of 8-mm diameters were used in this work as the milling media. The synthesized stainless steel powder particles were 
dispersed in ethanol, dropped down to a copper grid, and characterized by a transmission electron microscope (TEM, FEI-Tecnai G2F30).

The stainless steel powder was mixed with 6 wt.\% additive powder. To improve the homogeneity of the mixture and to obtain finer particles with a narrow particle size distribution, the mixture was milled in acetone for $1 \mathrm{~h}$, and dried at $70^{\circ} \mathrm{C}$. Afterwards, the mixture was encapsulated in evacuated quartz tubes and annealed at $900{ }^{\circ} \mathrm{C}$ for 15 min to soften the hard milled powders and thereby to improve compactability prior to compaction. The obtained powders were pressed using a single acting press at a pressure of $1 \mathrm{GPa}$ without any lubrication. The densification process was followed by sintering at 1000 and $1050{ }^{\circ} \mathrm{C}$ for $60 \mathrm{~min}$ and then water-quenching to room temperature. The distribution of the elements in the structure was analyzed via X-ray mapping (XMAP) by a scanning electron microscope (SEM, FEI-Quanta 200 FEG) operated at a voltage of $18 \mathrm{kV}$. The sintered materials were also studied by TEM, where for the sample preparation they were cut into a disk of $3 \mathrm{~mm}$ in diameter, ground to about $100 \mu \mathrm{m}$ in thickness, and then electropolished.

\section{Results and discussion}

The TEM micrograph, selected area diffraction (SAD) pattern, and high-resolution transmission electron microscope (HRTEM) micrograph of the as-milled stainless steel powder are provided in Fig. 1. As can be seen in Fig. 1a, the bright-field TEM micrograph includes nano-sized dark regions embedded in a bright matrix. It is noteworthy that in bright-field TEM images those crystallites which are close to a zone-axis orientation appear dark; in contrast, all crystallites which are far off a zone-axis orientation appear bright like amorphous phases. The related SAD pattern (Fig. 1b) includes some diffraction spots arising out of crystalline phases (austenite and ferrite) along with a halo pattern related to an amorphous phase, suggesting that the material has an amorphous/nanocrystalline structure. Fig. 1c presents the HRTEM micrograph of the same powder, in which a consideration to the atomic arrangement depicts a nanocrystal embedded in the amorphous matrix, inferring the heterogeneous nucleation of the amorphous phase from grain boundaries of the crystalline phases as high-energy places which are preferential for nucleation [14]. The significant structural refinement leading to nanocrystallization can be explained by severe plastic deformation due to the actions of the milling media [15] and the contribution of the interstitially dissolved elements of nitrogen [16-23] and carbon [24]. Moreover, amorphization is owing to severe plastic deformation (accordingly extreme structural refinement), large atomic size mismatch and negative enthalpy of mixing among the constituent elements [16-23,25].

Fig. 2 shows the SEM image and XMAP of Fe, $\mathrm{Cr}$, Mn, and Si for the additive-containing specimen sintered at $1000{ }^{\circ} \mathrm{C}$ in a scale comparable with the stainless steel particle size (SEM observations of the stainless steel powder suggested that the particles are almost $20 \mu \mathrm{m}$ in size [12]). Comparing Fig. 2a-d, it can be concluded that additive particles are embedded in the stainless steel matrix and no dissociation of Mn-Si additive particles has taken place. On the other hand, the SEM micrograph and XMAP of the elements of the specimen sintered at $1050^{\circ} \mathrm{C}$ are represented in Fig. 3, where a relatively uniform distribution of these elements can be observed. It implies that the additive in this sample is not stable and has been dissolved in the stainless steel alloy. The additive (Mn-11.5 wt.\% $\mathrm{Si}$ ) is a eutectic alloy with a eutectic temperature of $1040{ }^{\circ} \mathrm{C}$ [26]. That is, no liquation of this material occurs at temperatures less than the eutectic temperature, leading to a heterogeneous distribution of the elements for the samples sintered at $1000{ }^{\circ} \mathrm{C}$ where merely sluggish solid-state diffusion occurs. In contrast, the formation of the eutectic liquid phase at temperatures higher than the eutectic temperature results in wetting of the main powder particles, penetrating into the particle contacts and pore zones via capillary forces, and providing a path of high diffusivity $[8,9]$. These phenomena are responsible for the development of (a)

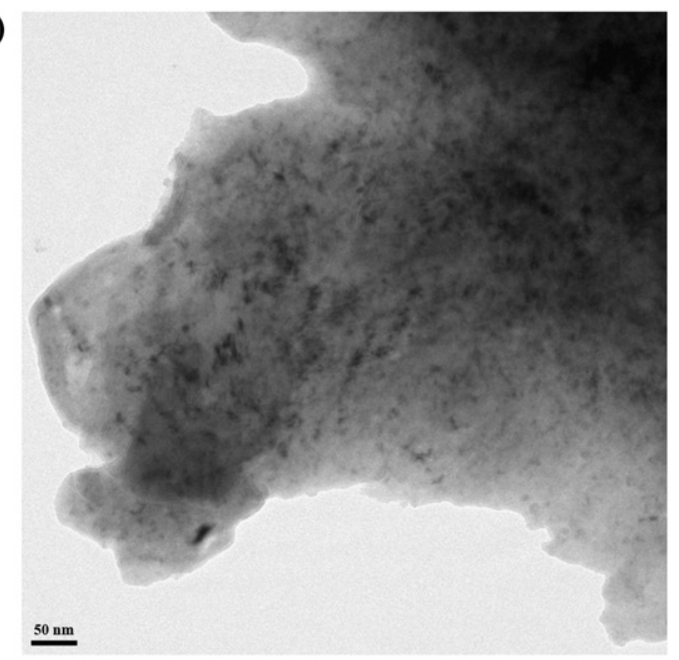

(b)

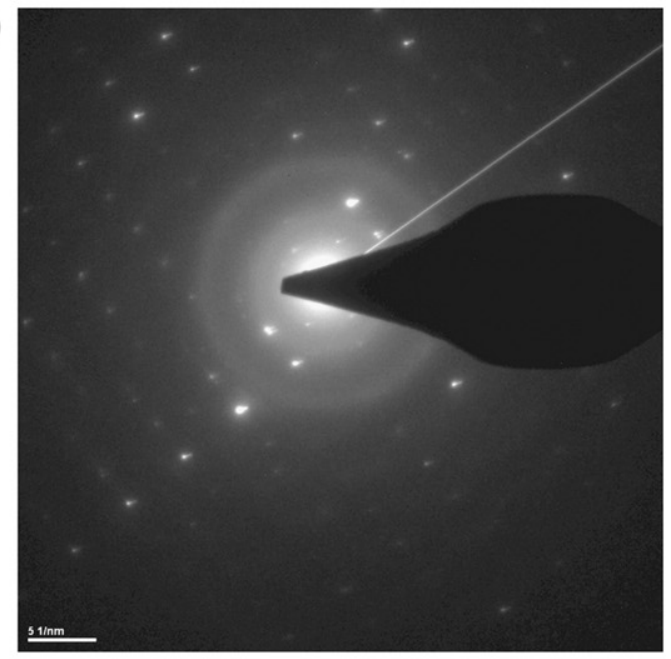

(c)

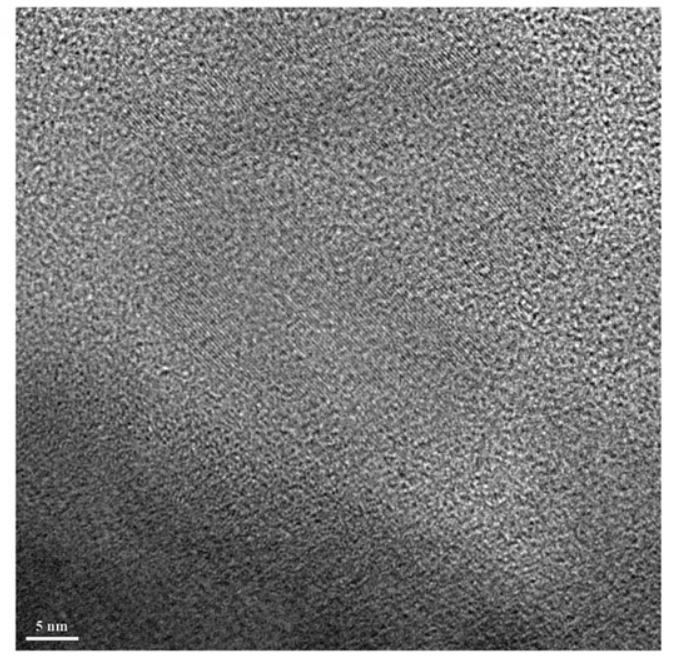

Fig. 1. TEM micrograph (a), SAD pattern (b), and HRTEM micrograph (c) of the asmilled stainless steel powder.

a uniform structure from the compositional distribution viewpoint in the sample sintered at $1050{ }^{\circ} \mathrm{C}$. In addition, the uniform distribution of $\mathrm{Cr}$ in the structure (Fig. 3b), which is critical for corrosion protection [27], infers the merit of processing.

The TEM micrograph and related energy dispersive X-ray spectroscopy (EDX) analysis of the sample sintered at $1000{ }^{\circ} \mathrm{C}$ are depicted in Fig. 4, where the EDX analysis of regions A and B indicated in the TEM 
(a)

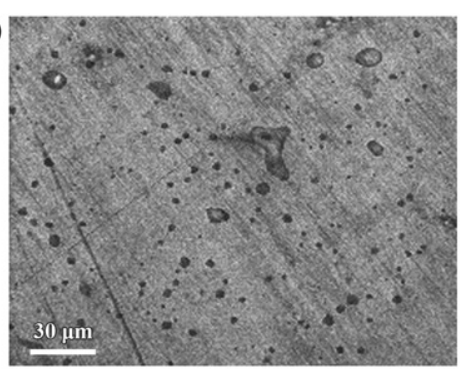

(c)

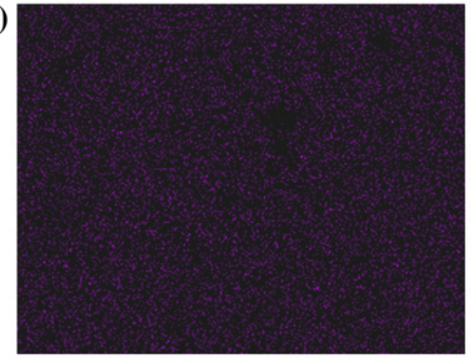

(b)

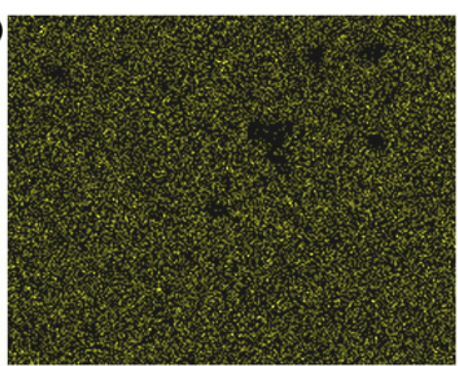

(d)

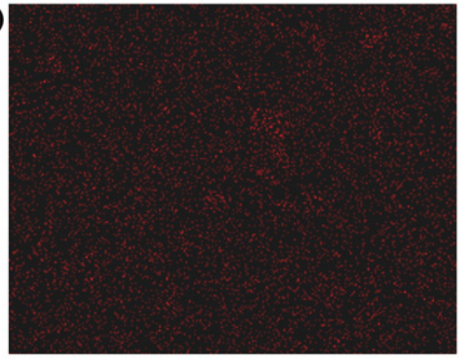

(e)

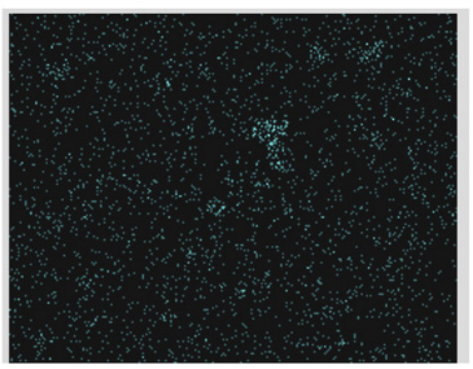

Fig. 2. SEM micrograph (a) and XMAP of Fe (b), $\mathrm{Cr}(\mathrm{c}), \mathrm{Mn}(\mathrm{d})$, and $\mathrm{Si}(\mathrm{e})$ for the additive-containing specimen sintered at $1000^{\circ} \mathrm{C}$.

(a)

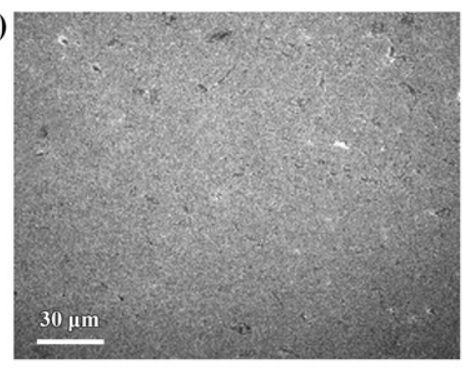

(c)

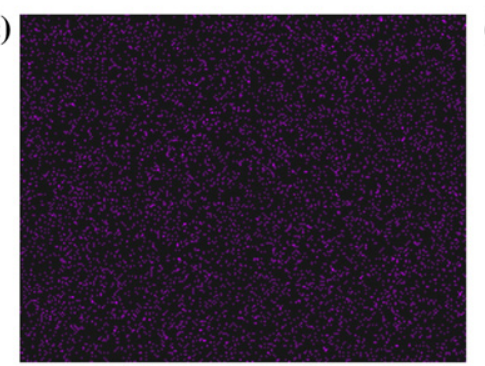

(b)

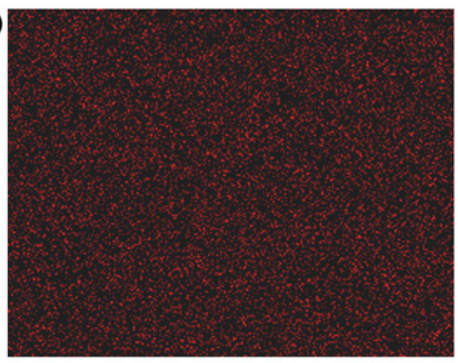

(d)

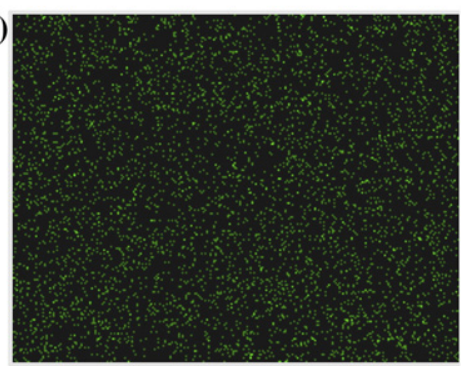

(e)

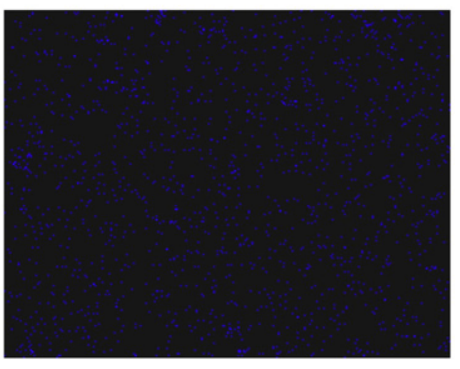

Fig. 3. SEM micrograph (a) and XMAP of Fe (b), $\mathrm{Cr}(\mathrm{c})$, Mn (d), and Si (e) for the additive-containing specimen sintered at $1050^{\circ} \mathrm{C}$. 
(a)

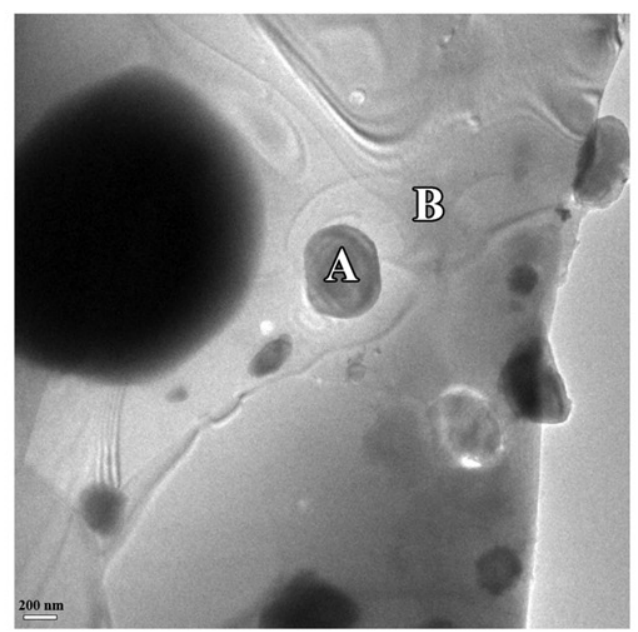

(b)

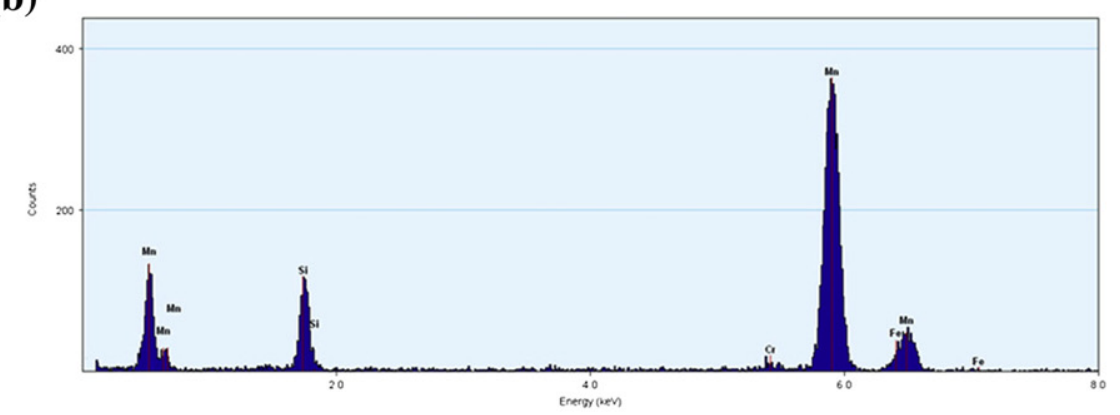

(c)

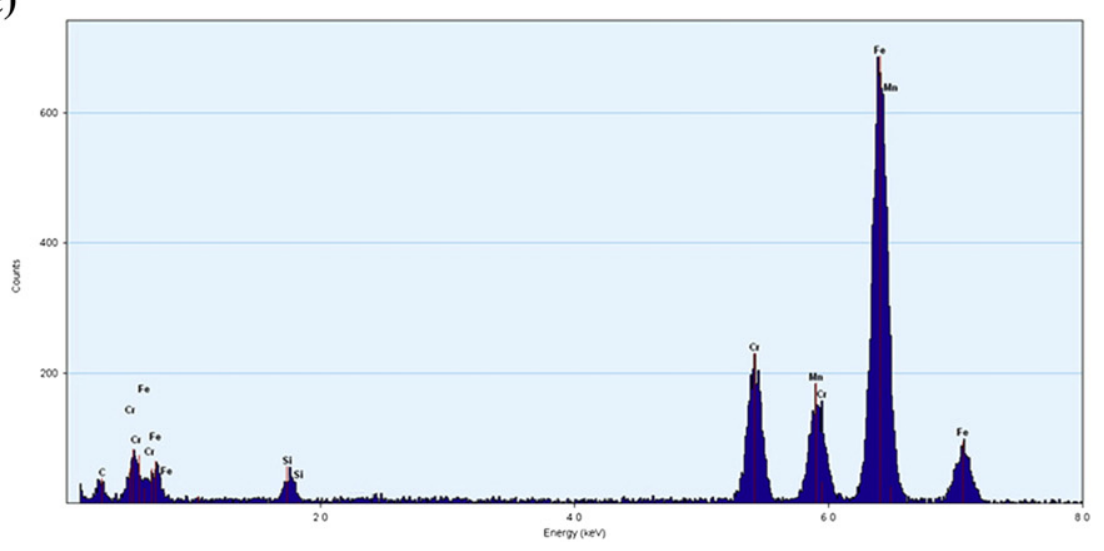

Fig. 4. TEM micrograph (a) and EDX analysis of regions A (b) and B (c) for the sample sintered at $1000{ }^{\circ} \mathrm{C}$.

image (Fig. 4a) are provided in Fig. 4b and c respectively. A consideration to the EDX analyses points out that dark regions, typically region $\mathrm{A}$, are $\mathrm{Mn}$ - and Si-rich zones which can be attributed to additive particles; in contrast, bright regions like region $B$ are related to the stainless steel matrix. That is, this analysis confirms the results of the SEM-EDX mappings, where a non-uniform distribution of the elements is realized after sintering at $1000{ }^{\circ} \mathrm{C}$. On the other hand, the TEM micrograph and related SAD pattern of the sample sintered at $1050{ }^{\circ} \mathrm{C}$ (Fig. 5) suggest a fullyaustenitic nanostructured material without any detectable evidence of the presence of additive particles, showing dissociation of Mn-Si additive particles. It would be worth mentioning that dark grains observed in the center of the micrograph are due to the fact that they are close to a zone-axis orientation and accordingly appear dark. A considerable thermal stability and inherent resistance to grain growth are responsible for the development of these nanostructures despite sintering, which is in agreement with other researches [28-33] conducted on multicomponent nanostructures synthesized by mechanical alloying and subsequent heat treatment. It is known that grain growth is strongly controlled by grain boundary diffusion and mobility. In this study, solute drag effects combined with the contribution of carbon and nitrogen are expected to retard grain growth. The solubility of the interstitially dissolved atoms of nitrogen and carbon in the crystalline phases is limited; thus, they tend to segregate at grain boundaries to decrease strain energy, thereby retarding grain boundary mobility [28-33].

\section{Conclusions}

In this paper, chemical composition uniformity in mechanicallyalloyed stainless steel (ASTM ID: F2581) sintered with a Mn-Si additive was studied via SEM, XMAP, TEM, and EDX. The outcome of this work is summarized as follows:

- Ball milling of the stainless steel powder for $48 \mathrm{~h}$ developed a nanocrystal dispersed amorphous matrix composite. 


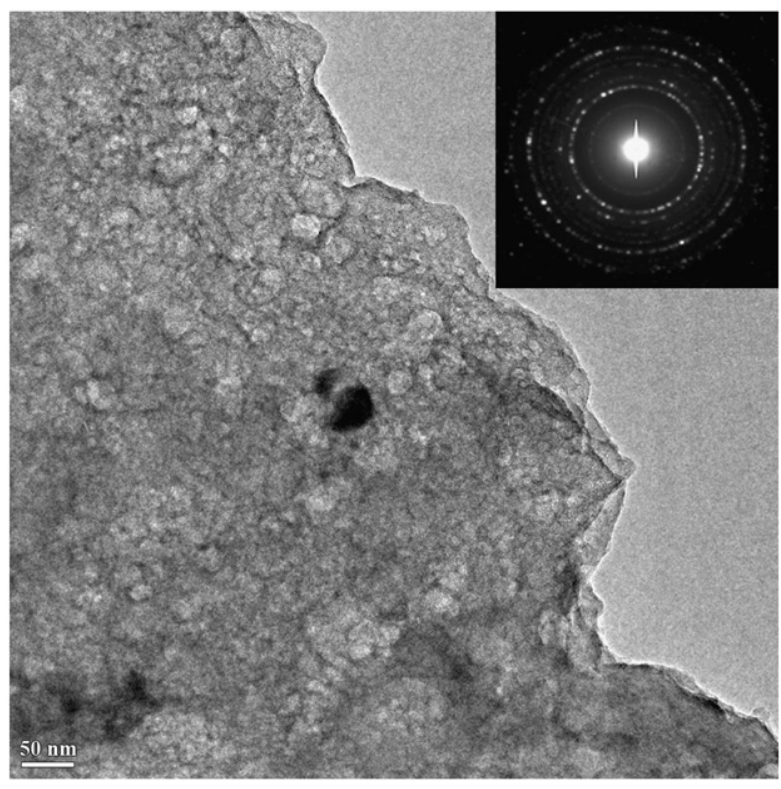

Fig. 5. TEM micrograph and SAD pattern of the sample sintered at $1050{ }^{\circ} \mathrm{C}$.

- After sintering at $1000{ }^{\circ} \mathrm{C}, \mathrm{Mn}-\mathrm{Si}$ additive particles were still embedded in the stainless steel matrix.

- Sintering at $1050{ }^{\circ} \mathrm{C}$ developed a relatively homogeneous microstructure from the chemical composition viewpoint, showing dissolution of the additive.

- A fully-austenitic nanostructured stainless steel was processed by mechanical alloying and subsequent sintering at $1050{ }^{\circ} \mathrm{C}$ with the $\mathrm{Mn}-\mathrm{Si}$ additive.

\section{Acknowledgment}

Parts of this work were supported by EU FP7 Marie Curie IRG Grant 239444, COST NanoTP, TUBITAK EEEAG Grants 108E163 and $109 E 044$ and TUBITAK BIDEB.

\section{References}

[1] K. Yang, Y. Ren, Sci. Technol. Adv. Mater. 11 (2010) 1-13.
[2] U.I. Thomann, P.J. Uggowitzer, Wear 239 (2000) 48-58.

[3] M. Fini, A.N. Nicoli, P. Torricelli, G. Giavaresi, V. Borsari, H. Lenger, J. Bernauer, R. Giardino, R. Chiesa, A. Cigada, Biomaterials 24 (2003) 4929-4939.

[4] L. Montanaro, M. Cervellati, D. Campoccia, C. Renata Arciola, J. Mater. Sci. Mater. Med. 17 (2006) 267-275.

[5] Y. Ren, H. Yang, K. Yang, B. Zhang, Key Eng. Mater. 342-343 (2007) 605-608.

[6] R.F.V.V. Jaimes, M.L.C.A. Afonso, S.O. Rogero, S.M.L. Agostinho, C.A. Barbosa, Mater. Lett. 64 (2010) 1476-1479.

[7] J. Buhagiar, L. Qian, H. Dong, Surf. Coat.Technol. 205 (2010) 388-395.

[8] R.M. German, Powder Metallurgy Science, 2nd ed., Metal Powder Industry Federation, 1994, pp. 99-109.

[9] E. Klar, P.K. Samal, Powder Metallurgy Stainless Steels: Processing, Microstructures, and Properties, ASM International, 2007, pp. 59-100.

[10] J.A.C. Miramontes, J.D.O.B. Sanchez, F.A. Calderon, A.M. Villafane, J.G.C. Nava, J. Mater. Eng. Perform. 19 (2010) 880-884.

[11] M. Youseffi, K.Y. Chong, Powder Metall. 46 (2003) 30-38.

[12] E. Salahinejad, M.J. Hadianfard, M. Ghaffari, Sh. Bagheri Mashhadi, A.K. Okyay, Mater. Lett. 74 (2012) 209-212.

[13] E. Salahinejad, M.J. Hadianfard, M. Ghaffari, Sh. Bagheri Mashhadi, A.K. Okyay, Metall. Mater. Trans. A 43 (2012) 2994-2998.

[14] E. Ma, M. Atzomon, Mater. Chem. Phys. 39 (1995) 249-267.

[15] C. Suryanarayana, Prog. Mater Sci. 46 (2001) 1-184.

[16] R. Amini, M.J. Hadianfard, E. Salahinejad, M. Marasi, T. Sritharan, J. Mater. Sci. 44 (2009) 136-148.

[17] E. Salahinejad, R. Amini, M.J. Hadianfard, Powder Technol. 215-216 (2012) 247-253.

[18] R. Amini, H. Shokrollahi, E. Salahinejad, M.J. Hadianfard, M. Marasi, T. Sritharan, J. Alloys, Compd. 480 (2009) 617-624.

[19] E. Salahinejad, R. Amini, M. Marasi, T. Sritharan, M.J. Hadianfard, Mater. Chem. Phys. 118 (2009) 71-75.

[20] R. Amini, E. Salahinejad, M.J. Hadianfard, M. Marasi, T. Sritharan, Mater. Sci. Eng. A 527 (2010) 1135-1142.

[21] E. Salahinejad, R. Amini, E. Askari Bajestani, M.J. Hadianfard, J. Alloys, Compd. 497 (2010) 369-372.

[22] R. Amini, E. Salahinejad, M.J. Hadianfard, E. Askari Bajestani, M. Sharifzadeh, J. Alloys, Compd. 509 (2011) 2248-2251.

[23] E. Salahinejad, R. Amini, M. Ghaffari, M.J. Hadianfard, J. Alloys, Compd. 505 (2010) 584-587.

[24] E.P. Yelsukov, G.A. Dorofeev, A.V. Zagainov, N.F. Vildanova, A.N. Maratkanova, Mater. Sci. Eng. A 369 (2004) 16-22.

[25] M. Mendez, H. Mancha, M.M. Cisneros, G. Mendoza, J.I. Escalante, H.F. Lopez, Metall. Mater. Trans. A 33 (2002) 3273-3278.

[26] ASM Handbook, Alloy Phase Diagrams, 3, ASM International, 2003.

[27] M.G. Fontana, Corrosion Engineering, 3rd ed. McGraw-Hill, NY, 1986.

[28] M.M. Cisneros, H.F. Lopez, H. Mancha, D. Vazquez, E. Valdes, G. Mendoza, M. Mendez, Metall. Mater. Trans. A 33 (2002) 2139-2144.

[29] E. Salahinejad, R. Amini, M.J. Hadianfard, Mater. Sci. Eng. A 527 (2010) 5522-5527.

[30] E. Salahinejad, R. Amini, M. Marasi, M.J. Hadianfard, Mater. Des. 31 (2010) 2259-2263.

[31] E. Salahinejad, R. Amini, M.J. Hadianfard, Mater. Des. 31 (2010) 2241-2244.

[32] E. Salahinejad, R. Amini, M. Marasi, M.J. Hadianfard, Mater. Des. 31 (2010) 527-532.

[33] R. Amini, E. Salahinejad, E. Askari Bajestani, M.J. Hadianfard, J. Alloys Compd. 509 (2011) 3252-3256. 